\title{
Proyectos musicales y nuevas formas de la visualidad performativa: el álbum visual Black is King de Beyoncé
}

\author{
Ana Sedeño-Valdellós \\ Universidad de Málaga \\ valdellos@uma.es
}

https://orcid.org/0000-0003-3897-2457

\section{Music projects and new forms of performative visuality: Beyoncé's visual album Black is King}

\begin{abstract}
RESUMEN
Black is King (2020), producto mediático secuela de El rey Leon (2019), es el nuevo proyecto de Beyoncé en colaboración con Disney, tercer álbum visual de su carrera y una propuesta narrativa globalizadora de naturaleza promocional dirigida a crear una experiencia mediática y cultural del artista para sus fans y oyentes. El videoclip musical mantiene su centralidad en el ecosistema mediático actual y ha conseguido adaptarse a las líneas de desarrollo de la comunicación transmedia. El álbum visual supone un formato en expansión en la industria de la música que permite organizar a largo los mensajes y alimentar una narrativa personal o texto-estrella para los artistas musicales. Black is King ha servido a Beyoncé para crear un storytelling que continúa el camino de otros trabajos anteriores, conecta con posiciones activistas frente a la comunidad afroamericana y materializa una experiencia visual y vivencial que tiene en la performance visualizada uno de sus componentes claves.
\end{abstract}

PALABRAS CLAVE

Álbum visual; Video musical; Beyoncé; Tratamiento del cuerpo; Storytelling; Performativo.

\section{ABSTRACT}

Black is King (2020), a media product sequel to The Lion King (2019), is Beyoncé's new project in collaboration with Disney, the third visual album of her career and a globalizing narrative proposal of a promotional nature, focus on creating a media and cultural experience of the artist for his fans and listeners. The music video maintains its centrality in the current media ecosystem and has managed to adapt to the lines of development of transmedia communication. The visual album is an expanding format in the music industry that allows messages to be organized and to feed a personal narrative or star-text for musical artists. Black is King has served Beyoncé to create a storytelling that continues the path of other previous works, connects with activist positions in front of the African-American community and materializes a visual and experiential experience that has in the visualized performance one of the key components of it.

KEYWORDS

Visual álbum; Music video; Beyoncé; Body reflection; Storytelling; Performance. 


\section{Performance musical y álbum visual en el universo cultural transmedia}

En el contexto cultural contemporáneo, las técnicas de creación de mensajes tienden a una mayor interrelación audiovisual, priorizando experiencias intertextuales, intermediales y de inmersión para el espectador, con el objetivo principal de controlar y dirigir la percepción a un consumo posterior. Con ellas, el capitalismo emocional fabrica subjetividad y la conduce desde y hacia los objetos consumibles. Las estrategias transmedia suponen uno de los últimos conjuntos de iniciativas empresariales que sirven tanto para publicitar las series de televisión de cadenas globales como para construir la imagen internacional de todo tipo de celebridades, también las musicales.

La producción discográfica resulta una práctica escasamente analizada desde los estudios transmedia, a pesar de que depende de fenómenos diversos en la industria creativa internacional, desde los subsectores audiovisuales hasta la moda y el diseño. No sólo debe atender a los procesos de registro musical (grabación, masterización, edición...) sino que sus productos deben ser promocionados y vendidos en todo tipo de formatos con o sin hibridación con banda visual: necesita de cartelería, videoclips, fotografías, redes sociales...Todas ellas construyen el llamado texto-estrella de Goodwin (1992) para celebridades, famosos, cantantes..

El capitalismo actual crea, recrea y reproduce este universo emocional con lógica transmedia para modificar estos mensajes diferenciados y adaptarlos a nuestros deseos, con un sentido de inmersión. En él cobra un novedoso rol la presencia física y el componente de performatividad de las acciones sociales mediadas: la performance tiene una nueva centralidad cultural. Los proyectos transmedia la emplean aplicando un método para la eficiencia de la dispersión, aprovechando al máximo los contenidos culturales generados en varios medios. Estos megaproyectos de promoción cultural dominan la esfera contemporánea y todos tienen en común una nueva materialidad ligada a la visualidad performativa: el cuerpo visualizado y mediado por todo tipo de imágenes se vuelve contenedor de significación, y en él confluyen sentidos desde diversas fuentes. En la música popular, el artista, su fisicidad y presencia mediática contiene el objeto máximo de representación: con él se da respuesta a todo tipo de intereses. Muchas de las propuestas de la música de grandes totems musicales, grupos de metal como Metallica, Marylin Manson, del pop como Lady Gaga... imponen una visualidad, transformada en diversos grados, de sus cuerpos en la mediación pública.

La encarnación del cuerpo en el mundo es un motivo de análisis contemporáneo fructífero en la actual sociología de la imagen y antropología visual. En Carnal Thoughts, Vivian Sobchack (2004) retoma los principios de la fenomenología de Merleau-Ponty para incluir una serie de reflexiones sobre la cultura comunicativa y su relación con el tiempo y recuerda que, en la contemporaneidad, los cuerpos son objetos y sujetos visuales con sentido. Sobchack busca revelar el papel del "pensamiento carnal" en la determinación del "significado vivido, la importancia y el valor no neutro" de las tecnologías perceptivas y sus representaciones" (2004, p. 160).

Los proyectos empresariales que introducen materiales y técnicas de promoción transmedia suponen una modificación de la mediación del cuerpo, de la creación de su significado a través de técnicas de circulación de imágenes novedosas, con efectos globalizadores sobre las percepciones sociales de los artistas musicales.

El videoclip se sitúa como un formato audiovisual central que recoge todos los experimentos de la comunicación transmedia. Sedeño-Valdellos, Rodríguez-López y Roger-Acuña (2016) hablan de postelevisiva al denominar a esta etapa de aceleración de su hibridación con otros medios y técnicas de creación visual. La variedad que soporta el video musical resulta de su naturaleza de formato poroso y maleable de las prácticas audiovisuales contemporáneas, casi una especie de contenedor de todas las potencialidades de lo visual en nuestra época.

El álbum visual es uno de los últimos formatos de diversificación del video musical y viene aumentando el interés académico dentro de los estudios visuales y medios digitales. Existen diversas modalidades pero todas combinan materiales visuales, sonoros y textuales con correspondencia de un track del álbum sonoro con un track visual: "producto audiovisual que tiene una relación directa con la música de un álbum del mismo artista" (Harrison, 2014, pp. 16-17). Con la omnipresencia de las redes sociales y la especialización por targets permite la circulación de estos contenidos de manera viral. Cara Harrison (2014) encontró mecanismos que compactaban o unificaban los mensajes o referentes de los diversos vídeos que los forman, a modo de motivos repetitivos (motivos temáticos, imágenes similares, localizaciones o personajes) y que ejercían de patrones de continuidad "a través del uso de leitmotivs visuales, que aluden a las narrativas ficcionales y personales" (Harrison, 2014, p.II.). Estos motivos visuales se convierten en temas, y funcionan frenando el carácter disperso o la heterogeneidad que puede venir dada de 10-11 mensajes simplemente yuxtapuestos, los vídeos musicales de un álbum visual.

Esta conciliación entre unidad y diversidad a través de figuras retóricas de repetición o de cita a otros textos culturales, hace al álbum visual un artefacto habilitado para componer storytellings, representaciones mentales globales (Herman, 2009, p. 197), al modo transmedia.

Black is King (2020), producto mediático secuela de El rey Leon (2019), es el nuevo proyecto de Beyoncé en colaboración con Disney, en la que la artista continúa con sus propuestas 
visuales/sonoras de larga duración.

\section{Los álbumes visuales de Beyoncé: Beyoncé, Lemonade y Black is King}

La artista norteamericana, Beyoncé Knowles-Carter tiene una trayectoria reconocida en el formato álbum visual. Beyoncé en 2013 y Lemonade en 2016, fueron producidos sin mucha información en redes sociales y su lanzamiento supuso una sorpresa para el mundo de la música.

Vendido como un novedoso concepto industrial que aunaba lo discográfico y lo audiovisual (un principio de lo transmedia), Beyoncé concentró la atención como primer trabajo en solitario del más exitoso miembro de Destiny's Child. Por el contrario, la cantante sumaba una supuesta independencia a su perfil comercial, aunque seguía la estrategia ya experimentada de PJ Harvey, Bjork, Nine Inch Nails, Coldplay y Sigur Ros. Desde el punto de vista de la musicología y los estudios culturales, Harper lo confirmaba argumentando que no existe el supuesto alejamiento de la industria del pop de Beyoncé con este álbum, mucho menos una ruptura. Por el contrario, su primer álbum visual, con novedosas técnicas virales, establece una fórmula altamente experimentada, un artefacto eficiente de creación de personajes o más bien "paquetes de identidad" (Harper, 2019) que se ayuda de un ecosistema preparado para socializar y viralizar los contenidos creados a partir del producto álbum.

Sostengo que evidencia una sinergia oportuna de una celebridad en particular y un ecosistema viral preparado: la capacidad de aprovechar simultáneamente las prácticas devocionales de los fanáticos y las prácticas de participación viral para vender de inmediato cientos de miles, y eventualmente millones, de álbumes (Harper, 2019, p. 62).

El segundo, Lemonade, habla de sororidad, hermandad entre mujeres y relaciones conyugales, junto a temas como el medio ambiente y la catástrofe del huracán Katrina en Nueva Orleans... Sus capítulos-vídeo están firmados por una palabra que describe estados de ánimo o fases: Intuición, Negación, Ira, Apatía, Vacío, Responsabilidad, Transformación, Perdón, Resurrección, Esperanza y Redención (Intuition, Denial, Anger, Apathy, Emptiness, Accountability, Reformation, Forgiveness, Resurrection, Hope and Redemption). Este storytelling "basado en el viaje de cada mujer hacia su autoconocimiento y curación" (Dubboff, 2016) apela a una doble vertiente de descripción de estados con un fondo narrativo: una lógica del estilo que se refuerza a través de experiencia (Ball, 2016).

La protesta mantiene una relación favorable con el pop y con sus productores y consumidores: hasta la contracultura se ha convertido en un espacio habitado y aprovechable para la industria musical. Con estos dos álbumes, la artista norteamericana ha consolidado una posición preferente en la industria musical global y ha instituido el álbum visual como forma hibrida entre lo ficcional y lo personal de la estrella, tanto que ha conseguido compatibilizar su posición preferente como megaestrella, con un compromiso y activismo feminista y en la defensa de causas de género e igualdad. Durham (2012) explica cómo negocia con su personalidad de mujer negra y construye su corporalidad, con alter egos como Sasha Fierce (Cashmore, 2010). Otras raperas como Janelle Monaé mantienen estrategias semejantes inspirándose en la reina del hip hop y la música negra, Marie J. Blige (Brooks, 2008). Esa motivación resulta rentable en términos de estrellato y visibilidad pública, si viene acompañada de un posicionamiento a favor de causas sociales o benéficas.

En cualquier caso, el álbum visual parece haberse convertido en un formato adecuado para artistas con ambición de estrellato unido a un compromiso social, como objetivo secundario de su desarrollo artístico. Todas parecen abonadas a él, por su facilidad para la gestión de un espacio digital específico (Cupid y Files-Thompson, 2016)

La pregunta es cómo se produce este proceso de creación de significado en un contexto global de producción masiva de contenidos y una lógica de la atención fragmentada por la saturación de información. Pregunta esencial para la música pop contemporánea, que valora un contenido mediático en tanto contribuye a diseminar sus textos culturales -canciones, álbumes- generando lógicas de consumo unidas a sentimientos individuales, de pertenencia a un grupo social y gestión del gusto, entre otros. Los artistas deben construir una narrativa propia, plena de sentido: el álbum visual lo permite escogiendo temas generales, apropiándose de motivos que ofrezcan mensajes abiertos a la interpretación del receptor, competente digital y con deseos de participación en este storytelling.

El álbum visual Black is King (en adelante BIK) supone así el tercer proyecto en este formato. El álbum sigue el storyline de El rey León, película desarrollada por Disney en 1994 y producida por la empresa de nuevo, en versión 3D en 2019. La alianza entre Disney y la artista Beyoncé Knowles-Carter suponía la concepción de un proyecto que tiene un lado musical The Gift, -temas musicales acompañados de un video a la manera clásica- y otro en forma de película, Black is King, con una serie de interludios que suponen cortas intervenciones en voz en off de personajes de la historia.

Las voces de casi todos los personajes protagonizan los interludios: Mufasa, protagoniza los dos primeros y en todos ellos se representa brevemente parte de la conocida trama que hace avanzar la historia.

La historia de BIK es la de un príncipe expulsado de su hogar siendo pequeño, tras la muerte de su padre, de cómo abandona su lugar, es ocupado por su tío, de su exilio a un mundo 
extraño, donde se produce su maduración y aprendizaje vital y de la vuelta o reconquista de su posición.

Esta historia de aprendizaje, redención y reconquista de su lugar y de su herencia supone una alegoría de la diáspora africana, cuando por la fuerza los negros fueron llevados a los Estados Unidos como esclavos, y hoy deben sentirse orgullosos de su legado. Tras dejar su lugar de origen (Bigger, Find your way Back), una etapa de múltiples tentaciones (el juego, el poder) que lo alejan de su destino (Don't jealous me y Jaara), el príncipe toma conciencia de su responsabilidad mediante el encuentro con una amiga de la infancia, su enamoramiento y regreso a su hogar (Water, Mood 4 Eva, Keys to the kingdom). A partir de aquí, el príncipe toma posesión de su herencia y se celebra su ascenso moral y simbólico y su asunción de responsabilidad con su comunidad. Este ciclo de vida/muerte está compuesto en BIK por una estructura episódica que alterna interludios y vídeos. En la Tabla 1 se han incluido los nombres de los primeros y segundos, junto al link de YouTube de los últimos.

\begin{tabular}{|c|c|}
\hline Títulos en Black is King & Títulos en Black is King \\
\hline $\begin{array}{l}\text { Balance } \\
\text { (Mufasa Interlude) }\end{array}$ & $\begin{array}{l}\text { Brown skin girl } \\
\text { https://www.youtube.com/ } \\
\text { watch?v=I_l1cYf_U58 }\end{array}$ \\
\hline $\begin{array}{l}\text { Bigger } \\
\text { https://www.youtube.com/ } \\
\text { watch?v=ZalRwnSRXhE }\end{array}$ & $\begin{array}{l}\text { Come Home } \\
\text { (Nala Interlude) }\end{array}$ \\
\hline $\begin{array}{l}\text { The Stars } \\
\text { (Mufasa Interlude) }\end{array}$ & $\begin{array}{l}\text { Keys to the kingdom } \\
\text { https://www.youtube.com/ } \\
\text { watch?v=boTsXJZxZeU }\end{array}$ \\
\hline $\begin{array}{l}\text { Find your way back } \\
\text { https://www.youtube.com/ } \\
\text { watch?v=_Gct9jnaVKY }\end{array}$ & $\begin{array}{l}\text { Follow Me } \\
\text { (Rafiki Interlude) }\end{array}$ \\
\hline $\begin{array}{l}\text { Uncle Scar } \\
\text { (Scar Interlude) }\end{array}$ & $\begin{array}{l}\text { Already } \\
\text { https://www.youtube.com/ } \\
\text { watch?v=agCgvFTJeRs }\end{array}$ \\
\hline $\begin{array}{l}\text { Don't jealous me } \\
\text { https://www.youtube.com/ } \\
\text { watch?v=LMTOJPorCDk }\end{array}$ & $\begin{array}{l}\text { Remember } \\
\text { (Mufasa Interlude) }\end{array}$ \\
\hline $\begin{array}{l}\text { Danger } \\
\text { (Young Simba \& Young } \\
\text { Nala Interlude) }\end{array}$ & $\begin{array}{l}\text { Otherside } \\
\text { https://www.youtube.com/ } \\
\text { watch?v=67Xnr4WVpCM }\end{array}$ \\
\hline $\begin{array}{l}\text { Ja ara e } \\
\text { https://www.youtube.com/ } \\
\text { watch?v=2DGErUXoX8I }\end{array}$ & $\begin{array}{l}\text { War } \\
\text { (Nala Interlude) }\end{array}$ \\
\hline $\begin{array}{l}\text { Run Away } \\
\text { (Scar \& Young } \\
\text { Simba Interlude) }\end{array}$ & $\begin{array}{l}\text { My power } \\
\text { https://www.youtube.com/ } \\
\text { watch?v=QPxtYb7Nedw }\end{array}$ \\
\hline $\begin{array}{l}\text { Nile } \\
\text { https://www.youtube. } \\
\text { com/watch?v=yaEij9bjxCl }\end{array}$ & $\begin{array}{l}\text { Surrender } \\
\text { (Simba \& Scar Interlude) }\end{array}$ \\
\hline
\end{tabular}

\begin{tabular}{|c|c|}
\hline $\begin{array}{l}\text { New Lesson } \\
\text { (Timon, Pumbaa \& } \\
\text { Young Simba Interlude) }\end{array}$ & $\begin{array}{l}\text { Scar } \\
\text { https://www.youtube.com/ } \\
\text { watch?v=QafjZuAl_cc }\end{array}$ \\
\hline $\begin{array}{l}\text { Mood } 4 \text { Eva } \\
\text { https://www.youtube.com/ } \\
\text { watch?v=ZHzoPgV7z_I }\end{array}$ & $\begin{array}{l}\text { I'm Home } \\
\text { (Mufasa, Sarabi \& } \\
\text { Simba Interlude) }\end{array}$ \\
\hline $\begin{array}{l}\text { Reunited } \\
\text { (Nalaga \& Simba } \\
\text { Interlude) }\end{array}$ & $\begin{array}{l}\text { Spirit } \\
\text { https://www.youtube.com/ } \\
\text { watch?v=civgUOommc8 }\end{array}$ \\
\hline $\begin{array}{l}\text { Water } \\
\text { https://www.youtube.com/ } \\
\text { watch?v=n1tzlafXUIY }\end{array}$ & $\begin{array}{l}\text { Black Parade } \\
\text { https://www.youtube.com/ } \\
\text { watch?v=iEQGRm-KUCO }\end{array}$ \\
\hline
\end{tabular}

Tabla 1. Interludios y vídeos de Black is King. Ana Sedeño-Valdellos

Esta configuración serial se antoja plenamente contemporánea, y rasgo ineludible de los álbumes visuales, como se comprueba en los estados por fases en Beyoncé, aquí con una fórmula nueva. Este relato abierto en su significación sigue el tipo de fórmulas alegóricas, siendo frecuentes en los mitos y otras narrativas africanas.

\section{Motivos visuales y storytelling}

Es mi proyecto más apasionado, para el que he estado grabando, editando e investigando día y noche durante el último año. Lo he dado todo y ahora es vuestro. Fue originalmente rodado como un complemento a la banda sonora The Lion King y está concebido para celebrar el halo y la belleza de negritud ancestral (Beyoncé, 2020).

Esto escribió Beyoncé para presentarlo en su cuenta de Instagram. El carácter personal de los proyectos musicales de Beyoncé, se ha aprovechado en algunas ocasiones para su promoción. entiende como personales y a los que dedica esfuerzo en documentación y preproducción. Incluso en el tráiler Beyonce aparece leyendo el libro Black Gods and Kings (1971), de Robert Farris Thompson.

Una característica global de los vídeos es la participación insistente de un número ingente de artistas y variado en su procedencia lo que permite nombrar como autores con un featuring a Blue Ivy Carter, Wizkid, Childish Gambino, Jay-Z, Kendrick Lamar, Burna Boy, Busiswa, Tierra Whack o Pharrell Williams -y más- todos músicos negros. Además, aparecen como parte del casting Lupita Nyong'o (modelo), Naomi Campbell (modelo), Kelly Rowland (compañera en Destiny Child), Jay-Z (marido), Ivy Z (hija), Salatiel (músico). Respecto a su participación Beyoncé ha declarado que representan "diversidad y conectividad". La mayoría de ellos tiene un rol específico en un solo episodio-video.

Hay que subrayar una suerte de diversidad extrema en las ambientaciones sugeridas, en su mayoría de clara referencia 
al imaginario paisajístico africano: desde desiertos, montañas, o praderas de bosque bajo, lagos y parques naturales hasta espacios urbanos luminosos y nocturnos. Interesante es comprobar que toda la información detallada del rodaje, preparación, datos técnicos, invitados, detalles de peluquería y vestuario... se encuentra en artículos, en un documental y en sites como la página específica del proyecto en Wikipedia: información completa que servirá para emplear como contenido de promoción y como sustento en su interacción con fans en las redes sociales. Otras posibles fuentes de negocio se derivan, incluso ajenos a la artista, como los probables circuitos turísticos en las localizaciones de rodaje, a modo de lo que ocurre ya en series y sagas cinematográficas. De hecho, BIK también es una película, así se vende en Disney+.

Los videos de BIK componen un fresco visual sobre la historia contada en The Lion King, ahíto de referencias y motivos visuales: "un tour-de-force de referencias a la historia negra, a las tradiciones africanas, a su propia familia y pasado". A continuación, querríamos destacar algunos de ellos, cuya recurrencia hace posible su caracterización como álbum visual, y sus derivaciones para el storytelling.

Bigger es un videoclip que vincula la creación del álbum al proyecto Disney El rey Leon, en el que hay una asociación entre el tema del nacimiento y de la herencia de padres a hijos y entre el tema de la película y la situación personal de Beyoncé, por la participación de su propia hija (Ivy) en el vídeo. En este y otros episodios, el videoclip explota la vida personal de la cantante estableciendo un paralelismo entre Simba y un joven niño (o niña) negro. El segmento se vincula especialmente a Otherside, que presenta más claramente este tema a través de una historia o cuento primigenio. Varios recursos visuales conforman una banda visual que deja una impronta de referencia a lo semítico, tanto en la vestimenta, como los colores tierra, amarillos y rojizos y la iconografía del niño abrigado con toquilla blanca en manos de mujer con tocado que más tarde es dejado en un río a modo del episodio bíblico de Moisés. Es decir, estos dos vídeos presentan y desarrollan el tema en cuanto a puesta en escena (presenta a personajes) y localización espacial y temporal: en este caso, la indefinición en estos términos se combina con las múltiples referencias a hechos bíblicos ampliamente conocidos por la memoria colectiva, como el bautismo (real en lo visual y espiritual en significación). Esta acción se vuelve un acto performativo en la historia, e inscribe la tradición cristiana del nacimiento de Jesús en el destino de un niño negro.

Otra característica común en ambos son los cuerpos maquillados de blanco y la centralidad de la figura de Beyoncé, como guía espiritual, chamán o consejero de la tribu -a modo de Rafiki-. Esto ocurre en Bigger, Otherside (maternidad) y Nile (luto y muerte por el padre de Simba, Mufasa). Esta tendencia a un simbolismo del color se establece desde el principio y se integra en la narrativa básica y muy conocida de la película, con conexión fácil a rituales religiosos del continente: en la República Democrática del Congo, las esculturas y los símbolos reales están cubiertos de polvo blanco, que simboliza una conexión espiritual con los antepasados y la gente de Punu en África Central usaba caolín, una arcilla blanca suave, para colorear artefactos y máscaras.

Un interés visual en el cuerpo y la performance sigue la diversidad de maquillajes, vestuarios y peinados con referencias a muchas culturas negras. Esto se ve especialmente en Spirit donde hay al menos 17 cambios de vestuario. Se conoce la especial atención que pone en vestuario y coreografía la artista y su colaboración con diferentes diseñadoras (Deviant La Vie, Lace By Tanaya, D.Bleu.Dazzled, A-Morir) permite la promoción cruzada entre la industria de la moda y la industria musical... Puede encontrarse información sobre cada modelo en las fuentes anteriormente mencionadas así como en el Instagram de Beyoncé.

Un personaje o presencia visual repetitiva es la de un hombre maquillado de azul y desnudo hasta la cintura, que se exhibe especialmente en Find your way back, Nile y Already: actúa de hilo conductor, guía espiritual y social, y parece tomado de la tradición Gullah, muy presente en afroamericanos en Virginia y Florida... Para encarnarlo se ha elegido al bailarín Stephen "Papi" Ojo que argumenta que imaginó su papel como el subconsciente de Simba, el príncipe, protagonista de la película: un personaje extradiegético. La piel azul tiene variados significados complementarios y contradictorios para la cultura negra esclavista: se usó para los techos de los cuartos de esclavos - Haint Blue (índigo) - y "representa el amor, la armonía, la unión y la paz (aunque su significado varía según el país)" (Glitter, 2020).

De igual manera, el cuerpo pintado de la artista a rayas verdes y negras en Find your way back -justo antes de recibir la estela de estrellas/bola de fuego en la que viene el príncipe a la tierra- representa la bandera panafricana y la diáspora continental.

Water es un video con cuadros o estampas en solitario de Beyoncé y otros grupos de bailarines, siempre negros, con diferentes vestuarios. Algo similar ocurre en Already, donde existen hasta 7 cambios de vestuarios/piel como puede comprobarse en la tabla 2 . El vídeo se configura centrándose en presentaciones de momentos, cuadros visuales heterogéneos, que significan por el propio mecanismo de montaje en yuxtaposición del videoclip. En realidad, esta técnica es básica en el videoclip conceptual contemporáneo, que habilita multiplicidad de identidades para el/la artista.

No se exagera si se insiste en la jerarquía del cuerpo y capacidad de transformación visual y de acción, como centro de creación de storytelling en BIK. Estudiando la configuración visual física y de gestos se comprueban repetitivos encuadres con una cuidada composición de la figura de Beyoncé como 

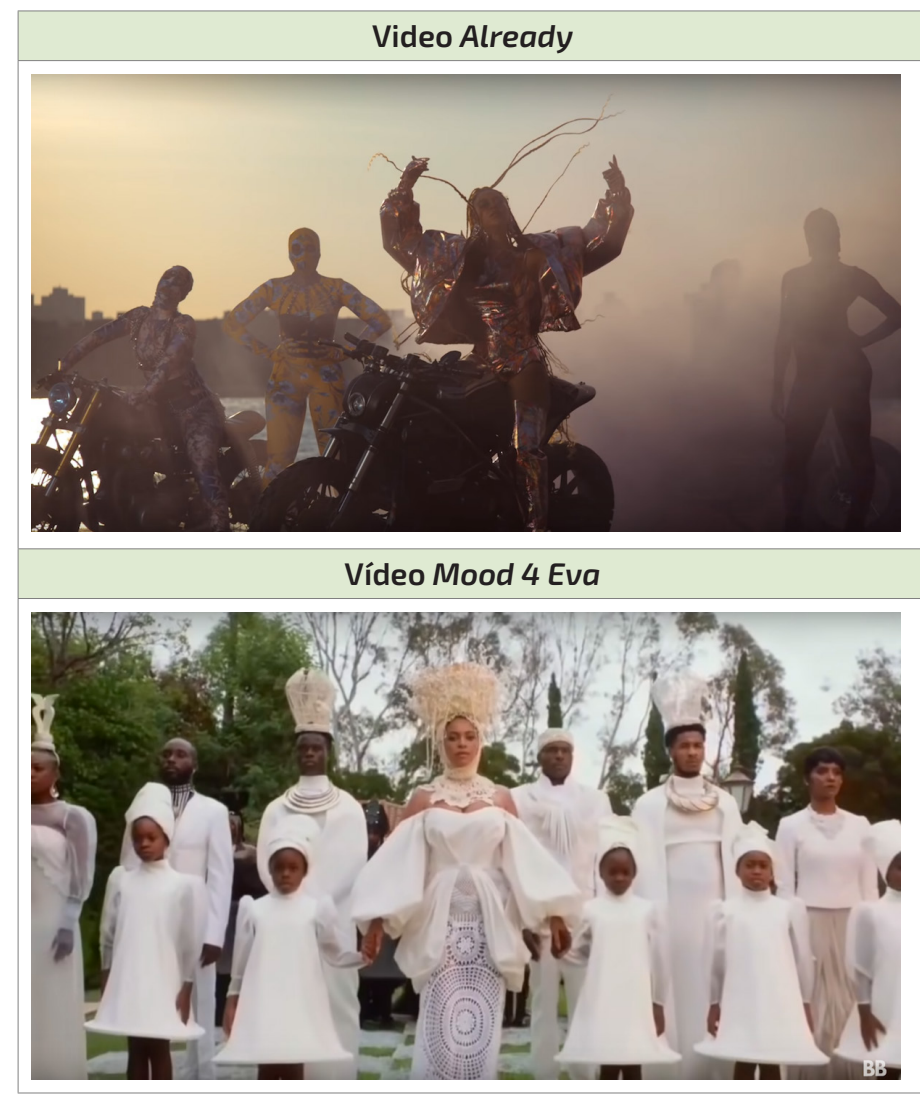

\section{Vídeo Find your way back}

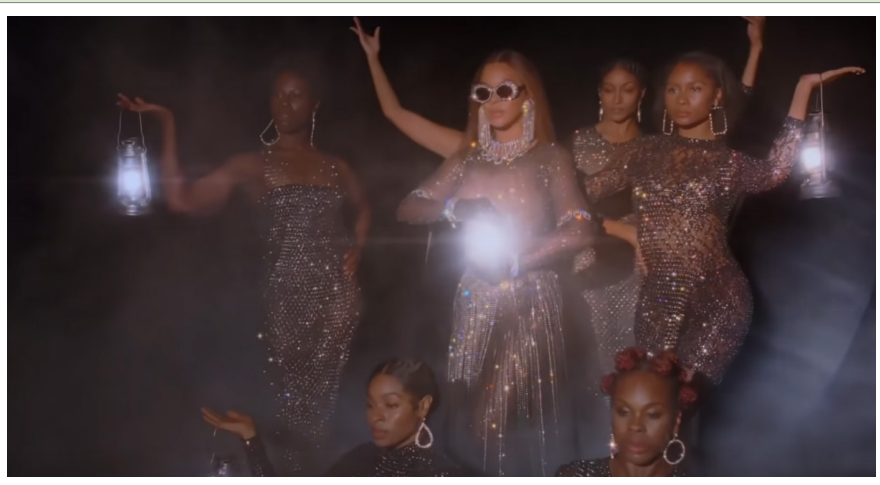

Vídeo Water

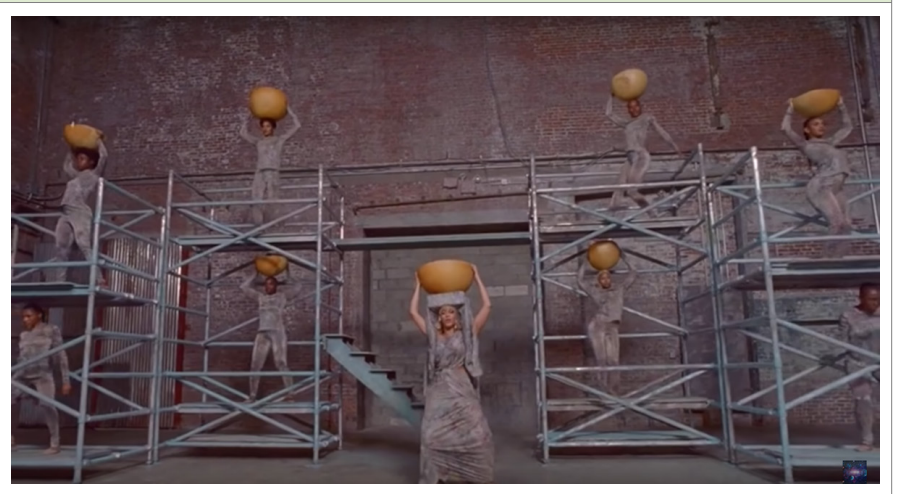

Tabla 2. Capturas de configuraciones-performance en diversos vídeos de Black is King. Elaboración propia.

elemento central. Nos referimos a un recurso consistente en un plano general a modo de tableau vivant, unido a veces con una realización basada en un travelling -leve, casi imperceptible- adelante o atrás. Suponen composiciones figurativas empleadas en otras ocasiones, y que marcan especialmente a Already, Find your way back, Mood 4 Eva o Water: cuadros en movimiento- de artista y cuerpo de baile o figurantes- que subrayan un aspecto escultural caro a Beyoncé. De hecho, no sólo ella sino Janelle Monaé en Dirty computer o Thierra Wack en Whack World, gustan de estas configuraciones visuales (Tabla 2).

\section{Intertextualidad en Black is King}

El cuerpo de la mujer negra en los medios de comunicación ha sido enfrentado profusamente por los estudios culturales que han asumido su objetualización física y los estereotipos en torno a ella (McGruder, 2006; Hooks, 1992; Kraaijvanger, 2018). Sin embargo, la feminidad que se plantea en BIK se desvía un poco. ). Lo musical como componente del proyecto se vuelve predominante a la narrativa clásica del cuento El rey León.

El cuerpo femenino en singular se encarna en Beyoncé: aunque el protagonismo pertenece al joven negro, Simba, la referencia constante a la cantante se comprueba en varios episodios, donde tiene un papel como actriz y actúa como personaje guía de la narrativa (es madre del personaje, pero también repre- senta la maternidad. Por otro lado, con frecuencia aparece rodeado de otras mujeres, siguiendo coreografías que remiten a tipos de danza como la Gbese, la Poco y la Kpakujemu de Nigeria, o el C'est Moi de Costa de Marfil. Esta insistencia conduce a considerar de nuevo al cuerpo en baile en el videoclip como forma de oratoria corporal, que equipara discurso y acción (DeFrantz, 2004, p. 66).

Un mensaje distintivo feminista de sororidad aparece en Brown skin girl (chica de piel marrón; Black is King se lee en inglés muy próximo a black skin, piel negra), situado en los salones donde las chicas de alta sociedad norteamericana realizan su debut ante los miembros de la comunidad. La puesta en escena aboga por una amistad intergeneracional en mujeres negras, encarnadas en familiares, amigas y colaboradoras, algunas mencionadas. La fotografía contrastada y producida sobre fondos de diversos colores, a modo de sesión de fotos de revista de moda, acompaña la letra "Tu piel como perlas. Lo mejor del mundo".

Otra peculiaridad en este carácter corporal central de BIK, se manifiesta en las continuas referencias a otros vídeos y trabajos visuales de la artista: la intertextualidad interna dentro de su storytelling se comprueba en variados momentos, como la lectura de prensa durante el desayuno en Mood 4 Eva, como en su famoso vídeo perteneciente a Lemonade, Partition. 


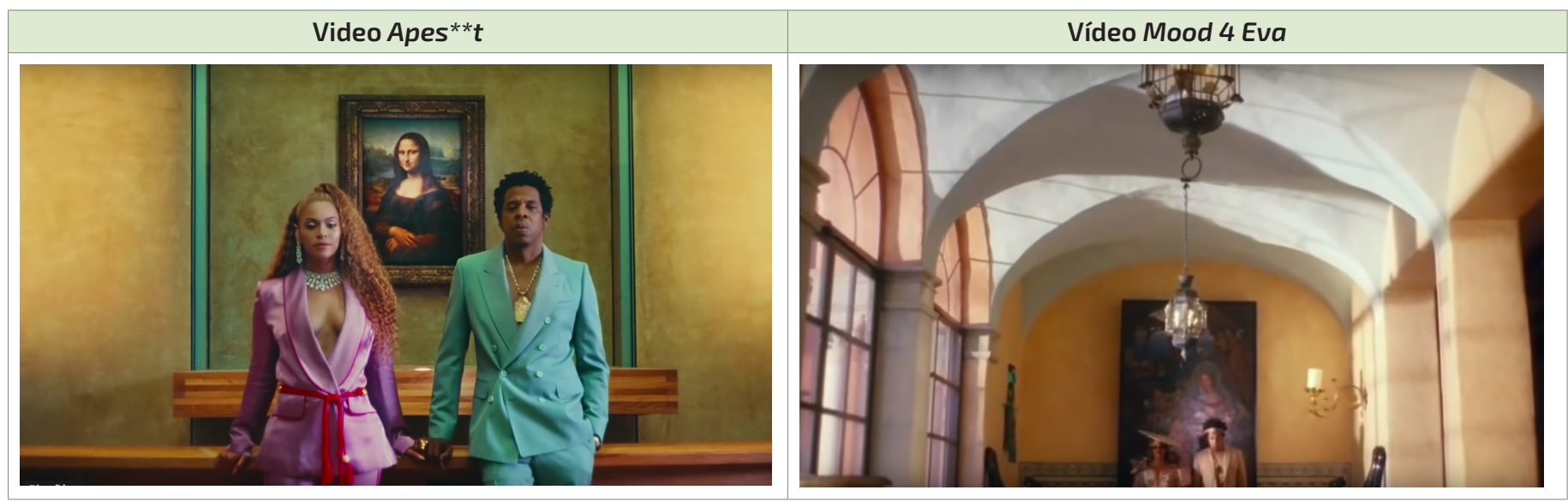

Tabla 3. Cita en Mood 4 Eva del vídeo Apes**t. Elaboración propia.

Las referencias directas y claramente reconocibles a otros vídeos se continúan con el empleo de la pintura como arte de la hegemonía blanca. En este caso, la copia figurativa con Apes**t aparece en Mood 4 Eva: Jay-Z y la artista actúan como pareja, estáticas mirando a cámara frente a un cuadro, donde aparece la Virgen María, con rostro de Beyoncé (Tabla 3).

Esta cita específica se configura a través del icónico recurso de tableau vivant, técnica artística que significa "cuadro vivo", que se ha descrito como reacción de sublimación de la crisis estética propia de la melancolía contemporánea (Kristeva, 1997) y como forma de manierismo cinemático (Petho, 2014, p. 64). Perniola (1995) dice que el tableau vivant (a través de diferentes caminos y de una manera distintiva) conecta no solo con las tendencias estilísticas globales en el cine, sino también, en parte, con lo que se puede captar en el encanto -abstracto, teórico- de "convertirse en una imagen" dentro de la cultura contemporánea. Esta figura supone un retorno a momentos históricos del arte donde las imágenes, religiosas sobre todo, dominaban el campo de la representación: su presencia sublime eclipsaba otras imágenes. Lyotard (1978) apunta a que en la postmodernidad el tableau vivant vuelve a modelos idénticos antiguos, fijando patrones de representación: sería una "figura de retorno" y de repetición:

La repetición y propagación de la igualdad, la reconexión repetida a una herencia cultural universal de grandes imágenes aprovecha su poder para coagular narrativas a su alrededor y en lugar de actuar como una interrupción, una pausa dentro del flujo de la narración, el tableau vivant se convierte en el prototipo de otras repeticiones y el punto focal de circular movimientos que construyen no tanto una narrativa lineal sino que ofrecen un plano de un panorama general, una visión integral y sugestiva del mundo (Lyotard, 1978, pp. 54-55).

En el álbum analizado se pueden observar innumerables tableau vivant que fijan momentos de composición del cuerpo, de los cuerpos: el cuerpo se vuelve visual en ellos, construyendo mediante sumas iconográficas una impronta de autenticidad del artista que fija y difunde su carisma, su estrellato. Es otra técnica que puede sumarse a otras que el videoclip como formato ha empleado para la construcción de textos estrella, que ha servido tanto a la música popular, y que es básica en su lógica cultural de engrandecimiento del productor/autor/intérprete de la música.

Beyoncé ha empleado esta figura estilística en otros momentos. El conocido videoclip Apes**t -en la que la familia Carter-Knowles consiguió que cerraran el Museo Louvre en París como localización- representa un interesante precedente de la operación de significado que pretende Beyoncé en sus creaciones visuales. Caticha (2020) argumenta que, en el vídeo, Beyoncé se erige en la nueva Madame Recamier, retratada en el cuadro por Jean-Louis David (1800) que se conserva en el Louvre. La elección del personaje, que protagonizó un caso de éxito en su ascenso social en la época de Napoleón Bonaparte -baluarte de la Europa invasora y colonizadora-, no resulta baladí y su situación en la parte central del video, en un impase musical, actúa dividiendo su sentido. La colocación de la pareja delante del mismo de manera icónica apunta a la voluntad de sustitución, y el viaje hacia nuevas jerarquías entre razas. En el video existe un gusto y una intención en revivir momentos pictóricos del arte clasicista europeo para subvertirlos y apropiarse de su significado, continuando con el reemplazo de las estatuas blancas con bailarines negros tiñéndolas de luz azul. La recreación visual del baile, del cuerpo individual y colectivo negro en un espacio (Louvre) fundado por (y que instituye) la hegemonía histórica de la cultura blanca, no solo es una reapropiación sino una provocación. Tales prácticas de imitación de cuadros eran forma de entretenimiento en el siglo XVIII (Chapman, 1992).

En Apesh** t, los Carter se apropian de este juego de salón autorreferencial como una analogía visual de su propio éxito en una cultura de racismo sistémico. Mientras que los bailarines encarnan actos de imitación que atraen nuestra atención a las obras maestras del Louvre, 
la negrura de los bailarines, que continuamente se pone en primer plano a través del vestuario, la coreografía y su mera presencia en tal institución, desestabiliza la relación mimética tradicional del cuadro vivo actor y obra de arte. Su negrura dificulta la capacidad de imitar completamente debido a la notoria ausencia de cuerpos negros y marrones en todo el museo "enciclopédico". Al politizar el tableau vivant, la puesta en escena de Madame Récamier por parte de los Carter es una crítica del estado omnipresente del mármol (blanco) en la conciencia europea. Su actuación subraya la peligrosa neutralización de la blancura, propagada en particular por el neoclasicismo y sus legados raciales, coloniales y capitalistas (Caticha, 2020).

Esta politización de la narrativa y de la visualidad apuntan al modo de hacer del afrofuturismo, una estética cultural y forma de utopía social, que combina ciencia ficción, fantasía e historia para alentar a los negros a recuperar su herencia y refundar el futuro desde la identidad negra ancestral. La ficción de Octavia Butler, Samuel Delany, N. K. Jemisin o Nnedi Okorafor se encuentran encuadradas en esta tendencia. El afrofuturismo quiere refundar la historia con personajes negros, activos y fuertes, reivindicando la posibilidad de definición de identidad y apuntando por una agenda feminista.

El éxito en el afrofuturismo tiene nombre de mujer y Black Parade, último videoclip de BIK, supone un desfile de la visualidad y puesta en escena de la diversidad negra, del poder femenino, resumiendo todo el albúm. Al igual que en todo videoclip la sección del último estribillo se despliega como ráfaga visual final que retoma momentos estelares, este videoclip desempeña una función de unir y fijar en la memoria del espectador, una especie de oda última a los valores y mensajes que se han desplegado en toda la película-album. A modo de palimpsesto con imágenes sobre todo de Already, Brown Skin girl o Mood 4 Eva -los más colectivos, con más personajes- trata de archivar final en torno al orgullo de pertenecer a un legado, a una historia, a un pueblo diverso y con futuro, mientras dice la letra: "Tenemos ritmo, tenemos orgullo (tenemos orgullo). Nacemos reyes (nacemos reyes), nacemos tribus (nacemos tribus). Santo río (río santo), lengua santa (lengua santa) (...) siente el amor (siente el amor)"1.

\section{Conclusiones}

Contar historias crea emociones o mas bien vínculos emocionales del lector con la historia, pues se ve directamente interpelado por ella. La performance musical contemporánea, tan unida al videoclip como formato, encuentra fórmulas de renovarse con el álbum visual, que supone una herramienta consciente para artistas musicales que desean construir narrativas o storytelling abiertos -incluso autobiográficos- a largo plazo. En primer lugar, representa la posibilidad de gestión de una identidad múltiple, con momentos pregnantes fabricados a través de la excelencia en composición visual, vestuario, peluquería y demás elementos de la puesta en escena. En segundo lugar, una nueva concepción de lo corporal forma una identidad fluida, adaptable en diversas plataformas digitales y redes sociales gracias a técnicas promocionales transmedia.

El protagonismo femenino se localiza en casi todos los vídeos de BIK: como guía, madre y conductora hacia una identidad común, Beyoncé encarna esta idea del necesario empoderamiento de la mujer, que debe desempeñar un rol activo en las historias. Esto continúa la trayectoria de apuesta por el cuerpo (femenino) y lo performativo, que mantiene después de los trabajos anteriores. Sin embargo, la corporalidad y su transfiguración en imagen, núcleo de esta performatividad visualizada, produce un salto cualitativo en el álbum analizado, convirtiéndose en activismo ejemplar por la causa afroamericana. Con ello se realiza una apuesta por un mensaje de empoderamiento de la comunidad negra utilizando ciertas ideas del panafricanismo y el afrofuturismo, movimientos actuales en el establecimiento de una agenda futura negra.

Si esto se completa con una estudiada intertextualidad de referencia a anteriores videoclips y a motivos visuales, el resultado toma forma de tejido denso de sentido, poroso y abierto al sentido para la interpretación del espectador o fan. Motivos visuales compuestos con homogeneidad, centralidad de la corporalidad estática o en movimiento y referencia al arte e imaginario africano construyen un común denominador de significación acorde con el texto-estrella de la artista.

Black is King es un artefacto mediático en el que, desde posicionamientos - y objetivos- empresariales transmedia se configura una narrativa, un storytelling reconocible -por su carácter de clásico de Disney- adaptado a la personalidad, la creación musical y el universo personal de la artista; un espacio digital propio.

En definitiva, un proyecto transmedia que se materializa en una experiencia visual y vivencial inmersiva para el espectador, donde los motivos visuales y las técnicas de realización y de cámara recurrentes combinan coherencia visual y serialidad con el cuerpo visualizado como estrategia textual uniformizadora, para la creación de un storytelling de empoderamiento de la comunidad afroamericana.

\section{Notas al final}

1. We got rhythm (We got rhythm), we got pride (We got pride) We birth kings (We birth kings), we birth tribes (We birth tribes) Holy river (Holy river), holy tongue (Holy tongue) Speak the glory (Speak the glory), feel the love (Feel the love) Motherland, motherland drip on me, hey, hey, hey Motherland, motherland drip on me, hey, hey, hey I can't forget my history, it's her-story Motherland drip on me, motherland, motherland drip on me 


\section{Referencias}

Ball, K. (2016). Beyonce's Formation. Film Criticism, 40(3). http:// dx.doi.org/10.3998/fc.13761232.0040.309

Beyonce (29 de junio de 2020) https://www.instagram.com/tv/ CCAMxfrHjAL/?utm_source=ig_embed

Brooks, D A. (2008). 'All That You Can't Leave Behind': Black Female Soul Singing and the Politics of Surrogation in the Age of Catastrophe. Meridians: Feminism, Race, Transnationalism, 8(1), 180-204. https:// doi.org/10.2979/MER.2008.8.1.180

Cashmore, E. (2010). Buying Beyoncé. Celebrity Studies 1(2), 135-50. https://doi.org/10.1080/19392397.2010.482262

Caticha, A. (2020). Madame Récamier as Tableau Vivant: Marble and the Classical Ideal in Beyoncé and Jay-Z's Apesh ${ }^{\star} t$, Journal18 https:// www.journal18.org/4513

Chapman, M.M. (1992). 'Living Pictures': Women and Tableaux Vivants in Nineteenth-Century American Fiction and Culture (Tesis Doctoral). Cornell University.

Cupid, J.A. y Files-Thompson, N. (2016). The Visual Album: Beyoncé, Feminism and Digital Spaces. En A. Trier-Bieniek (ed.), The Beyonce Effect: Essays on Sexuality, Race and Feminism. (pp. 94-108). McFarland \& Co.
Defrantz, T. F. (2004). The Black Beat Made Visible: Hip Hop Dance and Body Power. En A. Lepecki, (ed.). Of the Presence of the Body: Essays on Dance and Body Theory. Wesleyan UP.

Dubboff, J. (24 de abril de 2016). Beyoncé's New Album Lemonade Will Reportedly Drop on iTunes Sunday Night [Updated]. Vanity Fair. https://www.vanityfair.com/culture/2016/04/beyonce-lemonade-album-release

Durham, A. (2012). Check on It. Feminist Media Studies, 12(1), 35-49. https://doi.org/10.1080/14680777.2011.558346

Glitter (10 de agosto de 2020). The 'Blue Man' in Beyoncé's 'Black Is King' Has a Significant Hidden Meaning That You Need to Hear. Glitter. https://glittermagrocks.com/connect/2020/08/10/the-blue-man-inbeyonces-black-is-king-has-a-significant-hidden-meaning/

Goodwin, A. (1992). Dancing in the distraction factory: Music television and popular culture. University of Minnesota Press.

Harper, P. (2019). BEYONCÉ: Viral Techniques and the Visual Album. Popular Music and Society, 42(1), 61-81, https:/doi.org/10.1080/03007 766.2019.1555895

Harrison, C. (2014). The visual album as a hybrid art-form: A case study of traditional, personal, and allusive narratives in Beyoncé. (Tesis de Máster). Department of Arts and Cultural Sciences, Lunds University.

Hooks, B. (1992). Black Looks: Race and Representation. Routledge. del Grupo de Investigación en Documentación Digital y Comunicación Interactiva (DigiDoc) del Departamento de Comunicación de la Universitat Pompeu Fabra.

https://observatoriocibermedios.upf.edu/

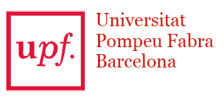

Departamento
de Comunicación Grupo DigiDoc

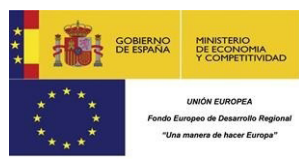

El Observatorio de Cibermedios (OCM) forma parte del proyecto del Plan Nacional "Narración interactiva y visibilidad digital en el documental interactivo y el periodismo estructurado". RTI2018-095714-B-C21 (MINECO/FEDER), Ministerio de Ciencia, Innovación y Universidades (España).

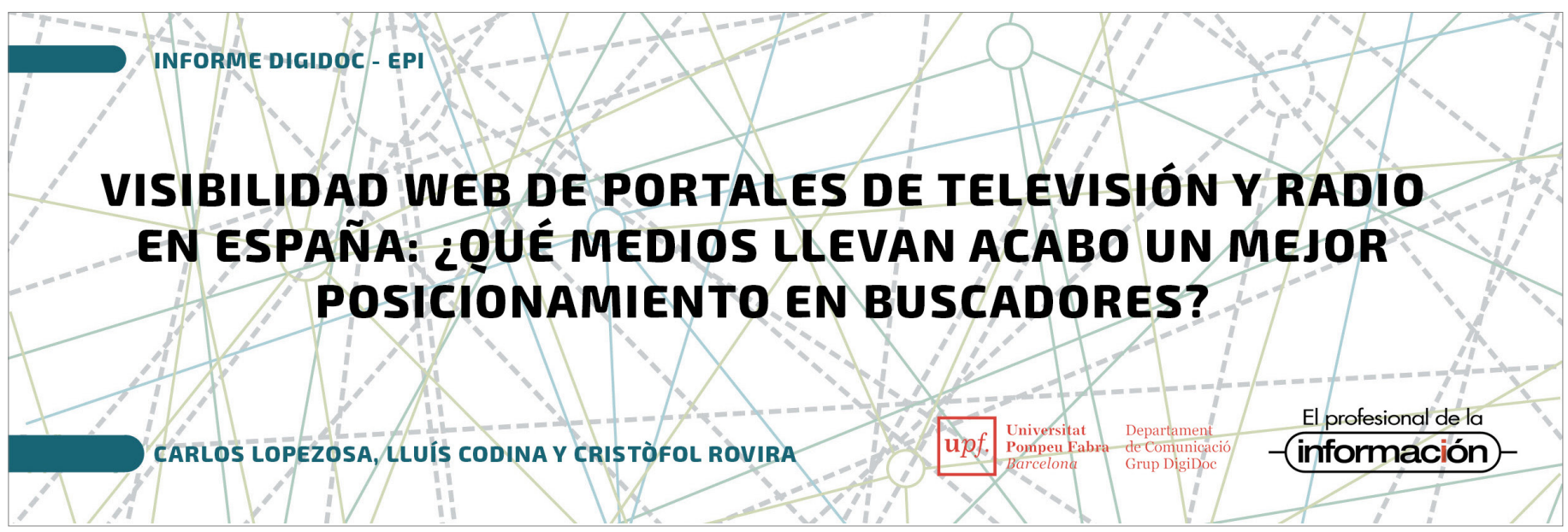


Kraaijvanger, J. (2018). Beyoncé: From Media Product to Black Feminist? (Tesis de Master). Radboud University Nijmegen. https://theses. ubn.ru.nl/bitstream/handle/123456789/6448/Kraaijvanger\%-

2c_J._\%28Janou\%29_1.pdf?sequence=1

Kristeva, J. (1997). Sol negro. Depresión y melancolía. Monte Ávila.

Lacasse, D. (2000). Intertextuality and hypertextuality in recorded popular music. En M. Talbot (ed.). The musical work: reality or invention? (pp. 35-58). Liverpool University Press.

Lyotard, J.F. (1978). Acinéma. Wide Angle, 2, 52-59.

McGruder, K. (2006). Pathologizing Black Sexuality: The U.S. Experience. En J. Battle, y S. Barnes (eds.), Black Sexualities: Probing Powers, Passions, Practices, and Policies. (pp. 101-114). Rutgers University Press.

Perniola, M. (1995). Enigmas. The Egyptian Moment in Societ and Art. Verso.

Petho, A. (2014). The Tableau Vivant as a "Figure of Return" in Contemporary East European Cinema. Acta Universia Sapientae Film and Media Studies, (9), 51-76. https://doi.org/10.1515/ausfm-20150003

Sedeño-Valdellós, A., Rodríguez-López, J., Roger Acuña, S. (2016). “El videoclip postelevisivo actual. Propuesta metodológica y análisis estético". Revista Latina de Comunicación Social, (71), 332-348. https://doi.org/10.4185/RLCS-2016-1098

Sobchack, V. (2004). Carnal Thoughts: Embodiment and Moving Image Culture. University of California Press.
Thompson, R.F. (1971). Black gods and kings : Yoruba art at UCLA. University of California, Museum and Laboratories of Ethnic Arts and Technology.

\section{CV}

Ana Sedeño Valdellós. Doctora en Comunicación Audiovisual y Profesora Titular en el Departamento de Comunicación Audiovisual y Publicidad de la Universidad de Málaga (España). Coordina el Máster de Creación audiovisual y Artes escénicas de la Universidad de Málaga. Sus líneas de investigación abordan la relación musicovisual en los medios, la música popular visualizada y las prácticas audiovisuales en el panorama contemporáneo, desde una perspectiva o histórica o educativa, con especial énfasis en hechos artísticos como el videojockey, el mapping o la videodanza. En relación con ellos ha publicado varios libros como "Lenguaje del videoclip", "La música contemporánea en el cine", "Análisis del cine Contemporáneo: Estrategias estéticas, narrativas y de puesta en escena" o "Historia del videoarte en España". Por otro lado, complementa esta labor con la de creadora audiovisual. Ha dirigido varias videocreaciones y un documental y ha desempeñado labores de directora de producción en varios videoclips y cortometrajes.
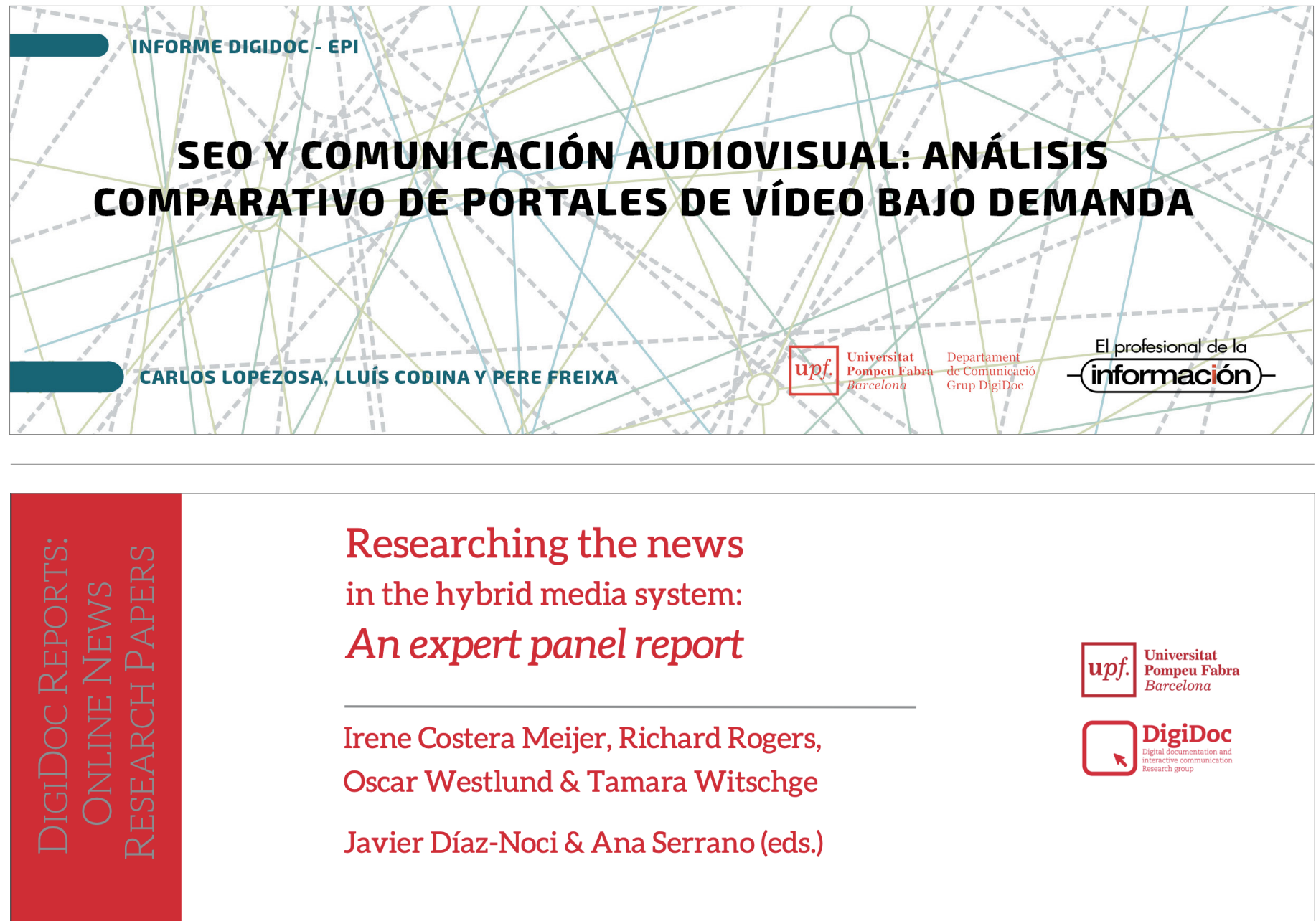

Researching the news

in the hybrid media system:

An expert panel report

upf. Universitat Pompeu Fabra
Barcelona

Irene Costera Meijer, Richard Rogers,

Oscar Westlund \& Tamara Witschge

Javier Díaz-Noci \& Ana Serrano (eds.) 